\title{
Fruit and vegetable intake among overweight and obese school children: A cluster randomised control trial
}

\author{
Rusidah Selamat ${ }^{*}$, Junidah Raib ${ }^{1}$, Nur Azlina Abdul Aziz ${ }^{1}$, Norlida Zulkafly ${ }^{1}$, \\ Ainan Nasrina Ismail ${ }^{1}$, W Nurul Ashikin W Mohamad ${ }^{1}$, Muhammad Yazid \\ Jalaludin $^{2}$, Fuziah Md Zain ${ }^{3}, Z_{\text {Zahari Ishak }}^{4}$, Abqariyah Yahya ${ }^{5}$ \& Abdul Halim \\ Mokhtar
}

${ }^{1}$ Nutrition Division, Ministry of Health Malaysia, Putrajaya, Malaysia; ${ }^{2}$ Department of Paediatrics, Faculty of Medicine, University of Malaya, Kuala Lumpur, Malaysia; ${ }^{3}$ Paediatric Department, Putrajaya Hospital, Putrajaya, Malaysia; ${ }^{4}$ Department of Educational Psychology and Counseling, Faculty of Education, University of Malaya, Kuala Lumpur, Malaysia; ${ }^{5}$ Department of Social and Preventive Medicine, Faculty of Medicine, University of Malaya, Kuala Lumpur, Malaysia; ${ }^{6}$ Department of Sports Medicine, Faculty of Medicine, University of Malaya, Kuala Lumpur, Malaysia

\begin{abstract}
Introduction: Adequate daily intake of fruits and vegetables is crucial for the prevention of chronic diseases. This study aimed to determine the effects of My Body is Fit and Fabulous at School (MyBFF@school) with nutrition education intervention (NEI) on the stages of change for fruit and vegetable intake among overweight and obese secondary school children based on the trans-theoretical model (TTM). Methods: This was a cluster randomised controlled trial involving 15 out of 415 eligible government secondary schools in central Peninsular Malaysia, which were randomly assigned into intervention (six schools; 579 school children) and control (nine schools; 462 school children). The intervention group was given NEI for 24 weeks, while the control group followed the existing school programme by the Ministry of Education. Results: There was no significant difference between the intervention and control groups for the stages of change, with majority at the maintenance stage after six months (intervention: 34.9\%; control: 39.0\%). The within group analysis showed a significant reduction after six months for those at the action stage (action and maintenance stage) from $68.0 \%$ to $60.4 \%$ in the intervention group and from $71.4 \%$ to $65.6 \%$ in the control group. However, there was a significant increase among those with adequate fruit and vegetable intake in the intervention group and no significant increase in the control group. Conclusion: MyBFF@school with NEI based on TTM provided acceptable changes in fruit and vegetable intake among overweight and obese secondary school children.
\end{abstract}

Keywords: Trans-theoretical model, nutrition education intervention, childhood obesity, secondary school children, cluster randomised controlled trial

\section{INTRODUCTION}

Adequate fruit and vegetable consumption is crucial for the prevention of chronic diet related non-communicable diseases such as heart disease, stroke and some cancers (van't Veer \& Kampman, 2007). The Malaysian Dietary Guidelines (MDG) 2010 recommends eating at least

\footnotetext{
*Corresponding author: Rusidah Selamat

Nutrition Division, Ministry of Health Malaysia, Level 1, Block E3, Complex E, Federal Government Administrative Centre, 62590, Putrajaya, Malaysia.

Tel: +603-88924404 ; Fax: +603-88924511; E-mail: rusidah.s@moh.gov.my /rusidah04@yahoo.com doi: https://doi.org/10.31246/mjn-2020-0023
} 
two servings and three servings of fruits and vegetables per day, respectively. Findings from the National Health and Morbidity Survey (NHMS) showed that there was a reduction from $48.4 \%$ in 2012 to $31.5 \%$ in 2017 of Malaysian adolescents who consumed at least two servings of fruits per day (IPH, 2013; IPH, 2017). Only $6.3 \%$ of adolescents consumed vegetables as recommended, although there was an increment to $7.8 \%$ in 2017 (IPH, 2013; IPH, 2017). Thus, it remains a great challenge for the country to ensure adequate intake of fruits and vegetables, particularly among adolescents.

Although there were studies reporting on the prevalence of adequate intake of fruits and vegetables among adolescents, there are however very few studies applying specific behavioural health models to assess the effects of fruit and vegetable intake using nutrition education intervention (NEI). Thus, one of the common behavioural models which is useful and used in fruit and vegetable consumption is the Trans-theoretical Model (TTM) (Vakili \& Khadem-Rezaiyan, 2016; Davoodi et al., 2017). The TTM consists of five stages of change, namely pre-contemplation, contemplation, preparation, action, and maintenance. Intervention programmes with TTM application is one of the effective ways to increase fruit and vegetable intake, encouraging those who are at pre-contemplation, contemplation, and preparation stages to change into an action/maintenance stage (Johnson et al., 2008; Davoodi et al., 2017).

Since behavioural change is a complex process which involves sequence of stages, assumption is usually made that the majority of them are not ready to change their behaviours. Thus, adolescents or school children might not consume fruits and vegetables because they are still at the pre-contemplation stage or are not aware of the importance of taking adequate fruits and vegetables. Despite that, there are also assumptions that individuals in the action and maintenance stages are more likely to have a higher intake of fruits and vegetables. Our study was conducted as little is known on the readiness of older adolescents or secondary school children to consume adequate fruits and vegetables. Since school children are spending most of their time in schools, school-based NEI could appear as one of the most effective strategies to educate and inculcate adequate intake of fruits and vegetables, particularly among overweight and obese secondary school children. It is important to understand the individual's behaviour and also to consider the stage of change of each individual target group before any nutrition education to increase their fruit and vegetable intake is undertaken. Therefore, this study was conducted with its aim to understand the effects of My Body is Fit and Fabulous at School (MyBFF@school) with NEI on the stages of change for fruit and vegetable intake based on TTM among overweight and obese secondary school children as compared to school children following the existing school nutrition and health programmes.

\section{MATERIALS AND METHODS}

The data collected were part of the MyBFF@school intervention study to combat obesity among Malaysian school children. The obesity intervention package for MyBFF@school comprised of nutrition education, physical activity, and psychology. One of the components in the NEI was the use of TTM to assess intake of fruits and vegetables. This study was a school-based cluster randomised controlled trial (Figure 1). Fifteen out of 416 eligible government secondary schools from the three states (Federal Territory of Kuala Lumpur, 


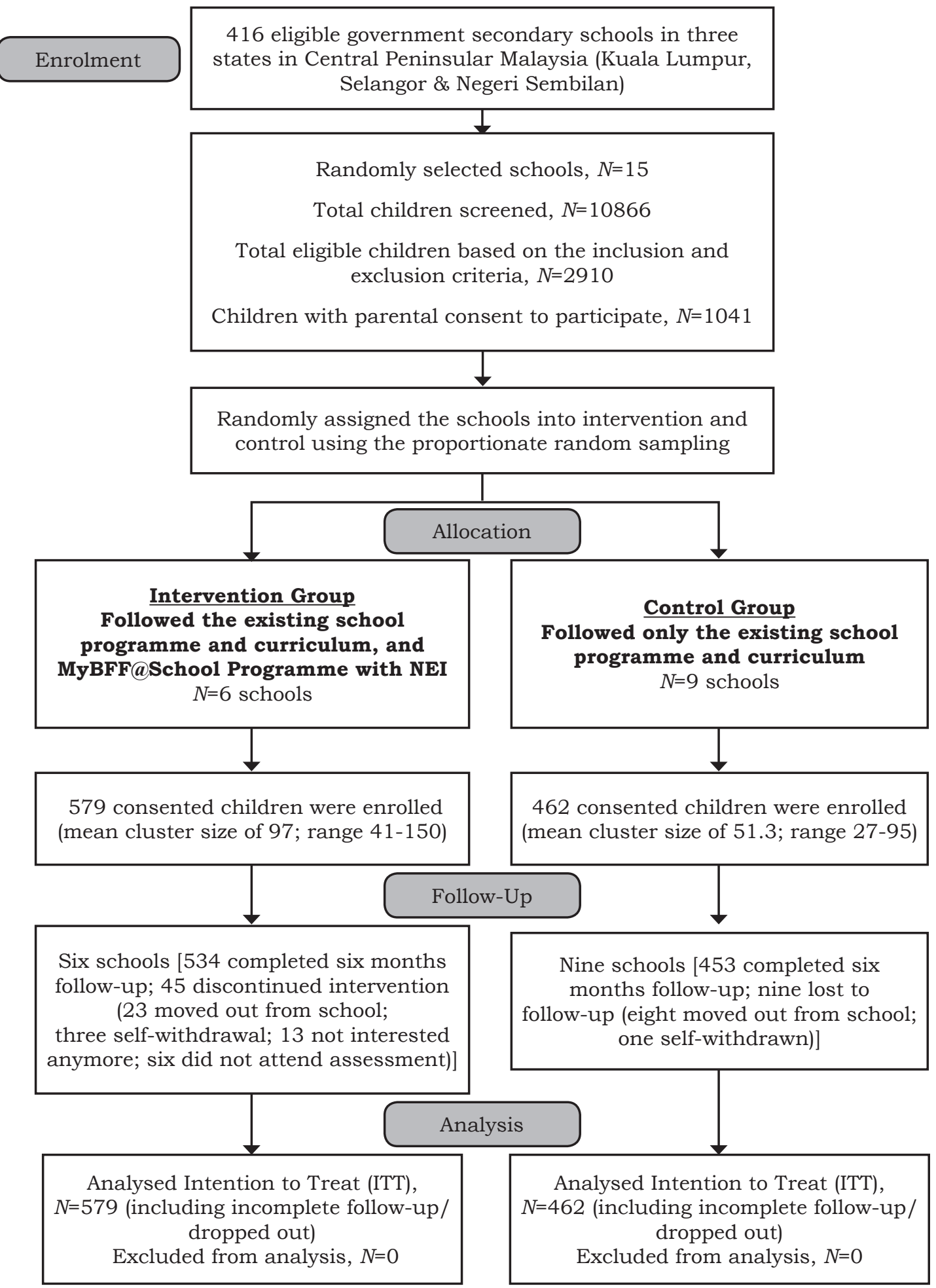

Figure 1. CONSORT diagram for nutrition component in MyBFF@school 
Selangor, and Negeri Sembilan) in central Peninsular Malaysia were randomly assigned into intervention (six schools; 579 school children) and control (nine schools; 462 school children), taking into consideration the urban and rural classification used by the Ministry of Education Malaysia. The government schools were wholly run by the central government. Thus, the target population were school children aged 13, 14, and 16 years old for participation in the study. Those aged 15 and 17 years old were excluded since they were involved in the National Examination. The intervention group undergone the MyBFF@school programme with NEI, while the control group remained with the current school nutrition and health programmes. This study was approved by the Medical Research and Ethics Committee, Ministry of Health Malaysia (NMRR NO: 13-439-16563) and was registered at ClinicalTrials.gov with Identifier: NCT04155255. Written informed consent was obtained from parents or guardian prior to the study.

\section{Nutrition education intervention (NEI)}

The NEI was specifically designed to tackle childhood obesity within the framework of the MyBFF@school programme. The Nutrition Education Module (NEM) consisted of five topics, which were divided into several subtopics. These five topics were, Wake up call/time to act; My body weight/know my body weight; Eat well, be well; Make a better life; and MyBFF. Some of the sub-topics covered included challenges in body weight loss and management, body weight status and risk factors, the importance of breakfast, fruit and vegetable intake, healthy meal preparation, smart shopping, and tips for eating out. NEI was carried out by trained personnels using the NEM during co-curriculum activities time after school hours for 24 weeks. NEI sessions were held once every two weeks for 4060 minutes per session at alternate weeks. The Malaysian Childhood Obesity Treatment Trial (MASCOTT) was used as a reference and guidance to develop the NEIs (Wafa et al., 2011). All NEIs were carried out using interactive methods with practical sessions.

\section{Trans-theoretical Model (TTM) for fruit and vegetable intake}

A validated TTM questionnaire for fruit and vegetable intake behaviour was adapted from Povey et al. (Povey et al. 1999). This TTM questionnaire or algorithm was also later adapted in 2014 by Wong et al. (2014). In summary, the TTM stages of change applied in our study were as follows:

i) Pre-contemplation: The individual does not intend or seriously think about increasing fruit and vegetable intake in the next six months.

ii) Contemplation: The individual does not plan to continue trying to increase fruit and vegetable intake over the next six months.

iii) Preparation: The individual does not plan to continue trying and confident that he/she can change his / her diet to increase fruit and vegetable intake over the next six months.

iv) Action: The individual has already increased consumption of fruit and vegetable in his/her daily diet or he/she has been eating five servings of fruits and vegetables daily for the past one month or within one to five months.

v) Maintenance: The individual has already been consuming at least five servings of fruits and vegetables daily for at least six months.

All the five stages of change have been collapsed or further categorised 
into pre-action (pre-contemplation, contemplation, and preparation) and action (action and maintenance).

\section{Nutrition attitude on fruit and vegetable intake}

The attitude of school children towards fruit and vegetable intake was assessed using a pre-tested questionnaire. A similar questionnaire was used for both pre- (baseline) and post(after six months) assessments. This questionnaire was developed by the MyBFF@school nutrition intervention component team. There were only two questions that measured fruit and vegetable attitude, as part of the fifteenitem nutrition attitude questionnaire. The attitude on fruit and vegetable was measured on a five-point Likert scale, ranging from strongly disagree (1 point) to strongly agree (5 points). There are two types of attitudes - positive and negative. For positive attitudes, the order of the Likert scale was as follows: strongly agree (5 points), agree (4 points), neutral (3 points), disagree (2 points), and strongly disagree (1 point). As for negative attitude, the order of the Likert scale was reversed as follows: strongly agree ( 1 point), agree ( 2 points), neutral (3 points), disagree (4 points), and strongly disagree (5 points).

\section{Intake of fruits and vegetables}

Fruit and vegetable intake was measured using a guided quantitative food frequency questionnaire (FFQ) for the past one week. In a guided quantitative FFQ, school children were guided by the interviewer to facilitate the understanding of serving size. This FFQ was developed using a similar approach for the FFQ on fruit and vegetable intake adopted from the WHO STEPwise Approach for Surveillance of NCD (WHO, 2005), which was previously used in the NHMS 2011 and NHMS 2015 in Malaysia. Therefore, no reliability and validity tests were conducted. Standard household utensils and food album were used to facilitate the quantifying of fruit and vegetable intake, which was later transformed into standard serving size measurements.

\section{Statistical analysis}

All the study data were managed using REDCap electronic data capture tool, which is a web-based application designed to support data capture for research studies (Harris et al., 2009). Data analyses were run using SPSS version 20 (SPSS Inc., Chicago, IL., USA). Descriptive statistics were used to present the baseline data. All analyses were based on the intention to treat analysis (ITT), taking into consideration dropped outs and incomplete data collection. Since loss to follow-up is often difficult to avoid in a randomised trial, the ITT principle was therefore used and it requires all participants in the trial to be included in the group regardless of any departure from the randomised treatment. In our study, the McNemar's test was used for within group analysis for categorical data to determine whether school children in the intervention and control groups who were at the pre-action stage (pre-contemplation, contemplation, and preparation) and action stage (action and maintenance) have changed after six months as compared to baseline. Chi-square test was applied for other categorical data. Independent t-test was used to compare the mean attitude on fruit and vegetable intake between groups, while paired t-test was used to analyse the mean intake of fruits and vegetables within the group at baseline and after six months. Results were considered statistically significant at $p<0.05$. 


\section{RESULTS}

\section{Characteristics of the respondents at baseline}

The demographic characteristics of the respondents at baseline from the cluster of six intervention schools ( $n=579$ school children) and nine control schools ( $n=462$ school children) are shown in Table 1. Overall, majority of the respondents were Malays (79.0\%), living in urban areas $(64.1 \%)$, and girls (58.7\%), with an equal percentage $(41.2 \%)$ of the respondents aged 13 and 16 years, respectively.

\section{The stages of change on fruit and vegetable intake}

Overall, there was no significant difference on the stages of change on fruit and vegetable intake between the intervention and control groups, both at baseline and after six months, although there was a slight reduction among those at the maintenance stage for both intervention and control groups at $34.9 \%$ and $39.0 \%$, respectively, as shown in
Table 2(i). However, the within group analysis showed a significant difference after six months, in which a reduction from $68.0 \%$ to $60.4 \%$ was observed for those at the action stage (action and maintenance stage) in the intervention group and from $71.4 \%$ to $65.6 \%$ in the control group.

\section{Intake of fruits and vegetables}

There was an overall significant increase in the adequate intake of fruits and vegetables after six months from $17.8 \%$ to $28.0 \%$ (McNemar $\left.\chi^{2}=17.99, p<0.01\right)$ in the intervention group and from $20.6 \%$ to $26.6 \%$ (McNemar $\left.\chi^{2}=4.54, p<0.05\right)$ in the control group (Table 3). However, the adequate intake of at least five servings of fruits and vegetables among those in the pre-action stage and action stage of the intervention group was only significantly increased from $25.9 \%$ to $36.2 \% \quad\left(\mathrm{McNemar} \chi^{2}=4.84, p<0.05\right)$ and from $14.0 \%$ to $24.1 \%$ (McNemar $\chi^{2}=12.86, p<0.01$ ), respectively (Table 3 ).

Table 1. Demographic characteristics of the respondents at baseline

\begin{tabular}{lccr}
\hline $\begin{array}{c}\text { Characteristics of the } \\
\text { respondents }\end{array}$ & $\begin{array}{c}\text { Intervention } \\
(N=579)\end{array}$ & $\begin{array}{c}\text { Control } \\
(N=462)\end{array}$ & $\begin{array}{c}\text { Total } \\
(N=1041)\end{array}$ \\
\hline Sex, $n(\%)$ & $234(40.4)$ & $196(42.4)$ & $430(41.3)$ \\
Boys & $345(59.6)$ & $266(57.6)$ & $611(58.7)$ \\
Girls & $330(57.0)$ & $337(72.9)$ & $667(64.1)$ \\
Location, $n(\%)$ & $249(43.0)$ & $125(27.1)$ & $374(35.9)$ \\
Urban & & & \\
Rural & $261(45.1)$ & $168(36.4)$ & $429(41.2)$ \\
Age groups, $n(\%)$ & $79(13.6)$ & $104(22.5)$ & $183(17.6)$ \\
13 years & $239(41.3)$ & $190(41.1)$ & $429(41.2)$ \\
14 years & & & \\
16 years & $486(83.9)$ & $337(72.9)$ & $823(79.0)$ \\
Ethnicity, $n(\%)$ & $32(5.5)$ & $30(6.5)$ & $62(6.0)$ \\
Malay & $58(10.0)$ & $95(20.6)$ & $3(14.7)$ \\
Chinese & $3(0.5)$ & $0(0.0)$ & $3(0.3)$ \\
Indian & & & \\
Others & $252(43.5)$ & $226(48.9)$ & $478(45.9)$ \\
BMI status, $n(\%)$ & $250(43.2)$ & $189(40.9)$ & $124(11.9)$ \\
Overweight & $77(13.3)$ & $47(10.2)$ &
\end{tabular}


Fruit and vegetable intake of obese school children

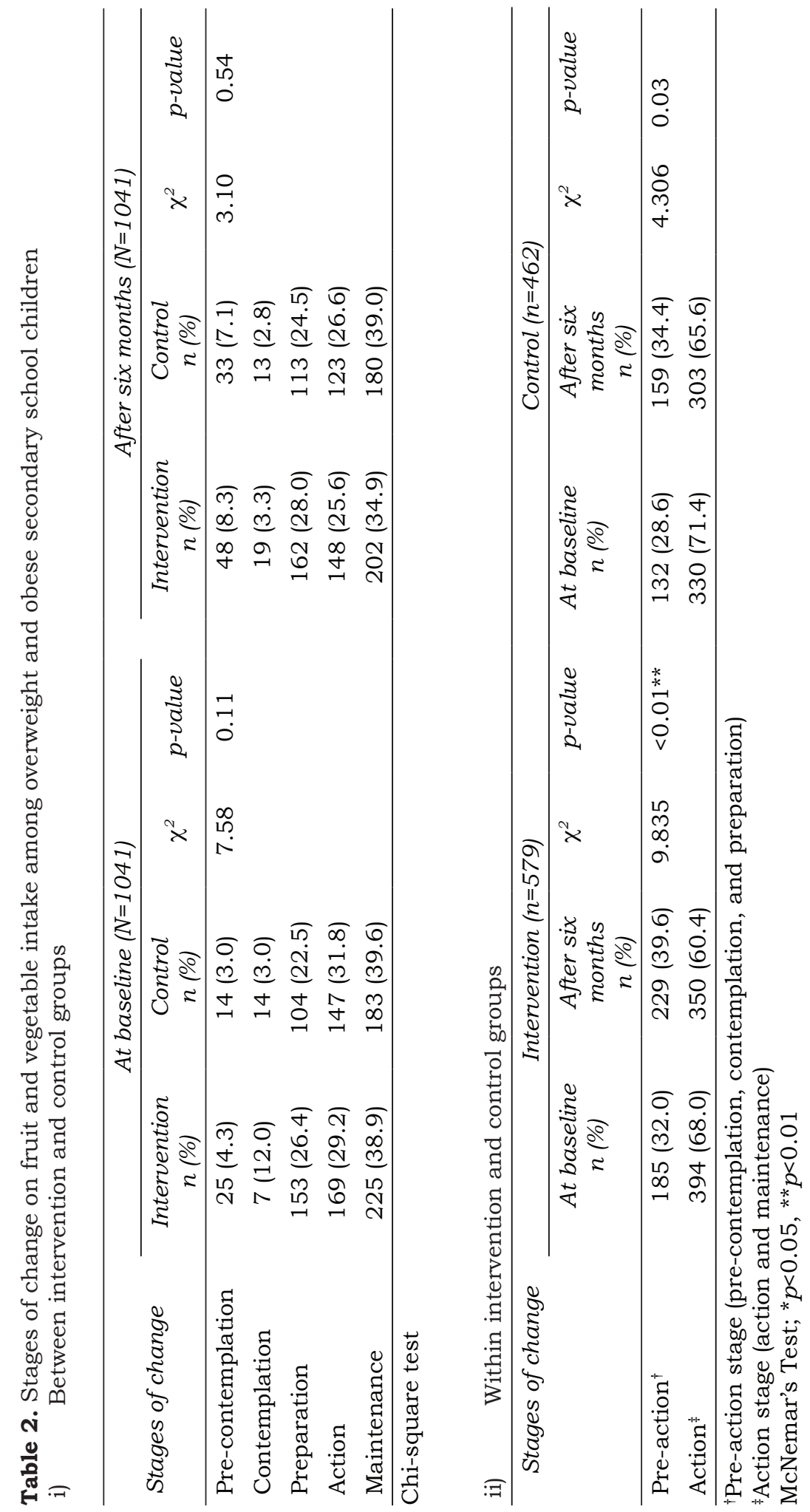




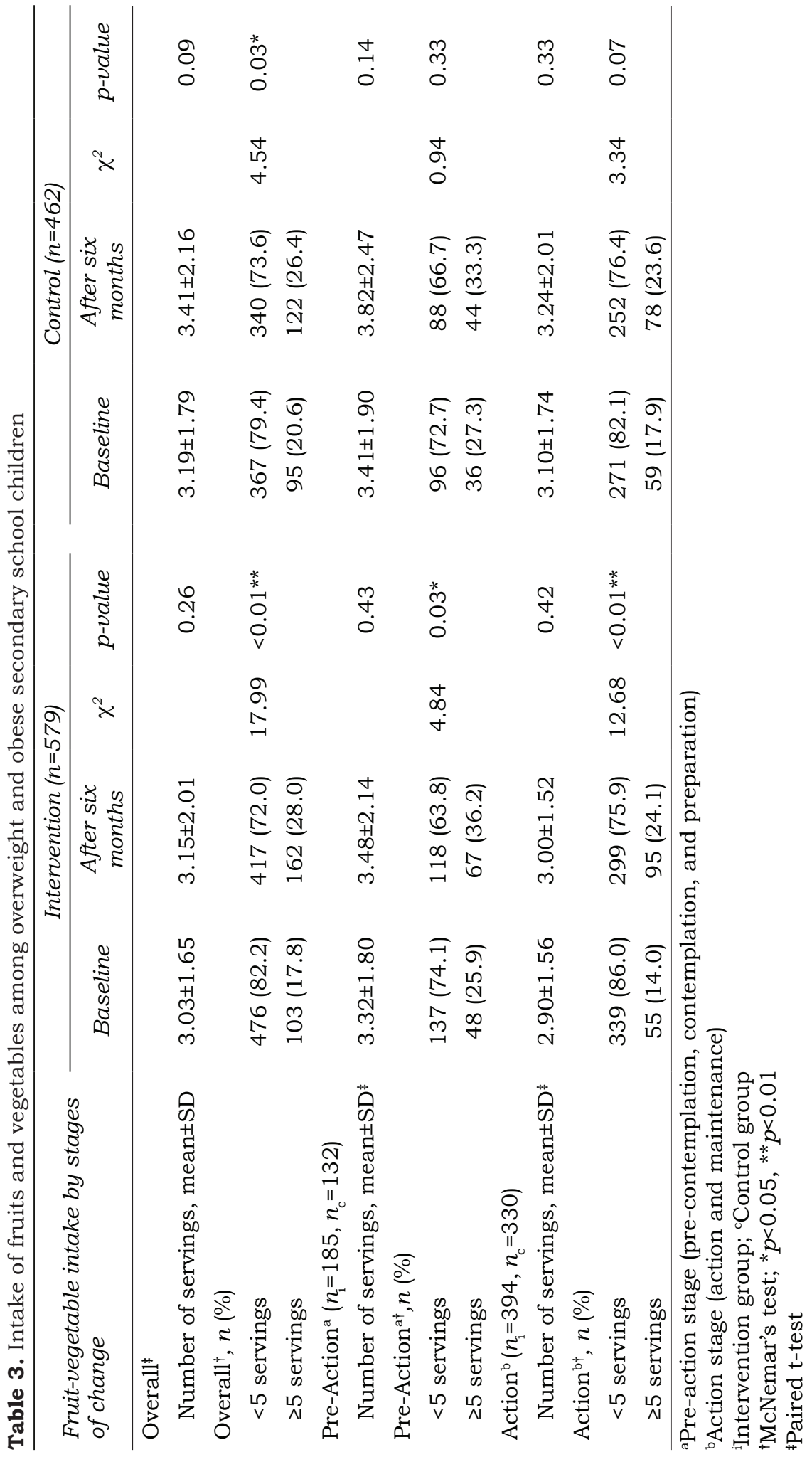


Although there was an overall increment in the mean intake of fruits and vegetables after six months, the mean number of daily fruit and vegetable intake were lesser than five servings and was not significant in both intervention and control groups (Table 3). Both NEI and existing school health education were thus found to have a positive effect on the adequate intake of fruits and vegetables among school children in this study.

\section{Attitude on fruit and vegetable intake by stages of change between groups}

Attitudes were represented by 'I like to eat fruits' (positive) and 'I don't like to eat vegetables' (negative). As shown in Table 4 , there was no significant difference on the attitude towards fruits for all stages of change, in both intervention and control groups at baseline. However, after six months, the only significant difference was noted for fruit intake at pre-contemplation. As for vegetable intake at baseline, although there was a significant difference between the intervention and control groups at preparation stage, there was however no significant difference after six months. In contrast, there was a significant difference in vegetable intake after six months at the maintenance stage.

Table 4. Attitude towards fruit and vegetable intake by stages of change

\begin{tabular}{|c|c|c|c|c|c|c|}
\hline \multirow{2}{*}{$\begin{array}{l}\text { Attitude towards } \\
\text { fruit and vegetable } \\
\text { intake according to } \\
\text { stages of change }\end{array}$} & \multicolumn{2}{|c|}{ At baseline } & \multicolumn{4}{|c|}{ After six months } \\
\hline & $\begin{array}{c}\text { Intervention } \\
(n=579) \\
\text { mean } \pm S D\end{array}$ & $\begin{array}{l}\text { Control } \\
(n=462) \\
\text { mean } \pm S D \\
\end{array}$ & $p$-value & $\begin{array}{c}\text { Intervention } \\
(n=579) \\
\text { mean } \pm S D\end{array}$ & $\begin{array}{l}\text { Control } \\
(n=462) \\
\text { mean } \pm S D\end{array}$ & p-value \\
\hline \multicolumn{7}{|l|}{ Pre-contemplation } \\
\hline I like to eat fruits ${ }^{\dagger}$ & $3.08 \pm 1.32$ & $2.36 \pm 1.65$ & 0.17 & $3.06 \pm 1.73$ & $2.12 \pm 1.58$ & $0.02^{*}$ \\
\hline $\begin{array}{l}\text { I don’t like to eat } \\
\text { vegetables }\end{array}$ & $2.72 \pm 1.02$ & $3.07 \pm 1.21$ & 0.34 & $2.42 \pm 1.03$ & $2.30 \pm 0.81$ & 0.60 \\
\hline \multicolumn{7}{|l|}{ Contemplation } \\
\hline I like to eat fruits ${ }^{\dagger}$ & $3.29 \pm 1.38$ & $3.79 \pm 1.37$ & 0.44 & $3.11 \pm 1.49$ & $3.69 \pm 1.18$ & 0.24 \\
\hline $\begin{array}{l}\text { I don’t like to eat } \\
\text { vegetables }{ }^{\ddagger}\end{array}$ & $3.14 \pm 1.07$ & $3.43 \pm 1.22$ & 0.61 & $3.63 \pm 1.01$ & $3.46 \pm 1.13$ & 0.66 \\
\hline \multicolumn{7}{|l|}{ Preparation } \\
\hline I like to eat fruits ${ }^{\dagger}$ & $4.29 \pm 0.81$ & $4.13 \pm 0.87$ & 0.15 & $3.95 \pm 1.17$ & $3.75 \pm 1.23$ & 0.18 \\
\hline $\begin{array}{l}\text { I don’t like to eat } \\
\text { vegetables }\end{array}$ & $3.63 \pm 1.32$ & $3.21 \pm 1.29$ & $0.01^{*}$ & $3.41 \pm 1.32$ & $3.44 \pm 1.26$ & 0.83 \\
\hline \multicolumn{7}{|l|}{ Action } \\
\hline I like to eat fruits ${ }^{\dagger}$ & $4.37 \pm 0.83$ & $4.35 \pm 0.85$ & 0.84 & $4.03 \pm 1.09$ & $4.15 \pm 0.93$ & 0.31 \\
\hline $\begin{array}{l}\text { I don’t like to eat } \\
\text { vegetables }\end{array}$ & $3.38 \pm 1.33$ & $3.56 \pm 1.32$ & 0.23 & $3.34 \pm 1.20$ & $3.50 \pm 1.28$ & 0.32 \\
\hline \multicolumn{7}{|l|}{ Maintenance } \\
\hline I like to eat fruits ${ }^{\dagger}$ & $4.54 \pm 0.67$ & $4.57 \pm 0.73$ & 0.66 & $4.37 \pm 0.81$ & $4.32 \pm 0.79$ & 0.59 \\
\hline $\begin{array}{l}\text { I don't like to eat } \\
\text { vegetables } ¥\end{array}$ & $3.88 \pm 1.30$ & $3.96 \pm 1.23$ & 0.54 & $3.76 \pm 1.31$ & $4.02 \pm 1.12$ & $0.04^{*}$ \\
\hline $\begin{array}{l}5 \text {-point Likert scale } \\
\text { 1-strongly disagree) } \\
\text { ‡5-point Likert scale } \\
\text { 5-strongly disagree) } \\
\text { Independent t-test; * }\end{array}$ & 05 & & & & & \\
\hline
\end{tabular}




\section{DISCUSSION}

Our present study was undertaken to assess the effects of NEI on the stages of change in the daily consumption of fruits and vegetables among overweight and obese older school children. A within group analysis in our study showed that the school children who were at the pre-contemplation, contemplation, and preparation stages at baseline or prior to the programme constituted $32.0 \%$ of those in the intervention group and $28.6 \%$ in the control group. In contrast, $29.2 \%$ and $31.8 \%$ of the children in the intervention and control groups were at the action stage, respectively, which indicated that they had already been consuming at least five servings of fruits and vegetables for less than six months. The findings of our study also showed that at baseline, $38.9 \%$ and $39.6 \%$ of school children for both intervention and control groups were at the maintenance stage, respectively. This indicated that these groups of school children had already had at least five servings of fruits and vegetables per day for at least six months and were trying to avoid relapse. However, the findings of our study observed a slight reduction or some relapse among those at the maintenance stage after six months, with only $34.9 \%$ for the intervention group and $39.0 \%$ for the control group.

There was a significant difference after six months, whereby a reduction was observed from $68.0 \%$ to $60.4 \%$ in the intervention group and from $71.4 \%$ to $65.6 \%$ in the control group of those at the action stage (action and maintenance stage). However, there was a significant increase (McNemar's Test, $p<0.05$ ) in the percentage of those with adequate intake of at least five servings of fruits and vegetables daily in the intervention group - from $25.9 \%$ to $36.2 \%$ for those at the pre-action stage and from 14\% to $24.1 \%$ for those at the action stage.
It was reported that individuals who are at the action stage (action and maintenance stage) are more likely to follow a better diet than individuals in the pre-action stage, with a higher consumption of fruits and vegetables in older adults (Greene et al., 2004). The findings of our study are however not consistent with the findings of this mentioned study and also a schoolbased obesity intervention designed to improve nutrition and physical activity habits among slightly younger American adolescents aged 12 years for the same duration. In this study, it was reported that most respondents were in the action stage after the intervention (Purswani et al., 2017), thus such intervention is beneficial to increase fruit and vegetable consumption among school children. In our study, despite a slight reduction of those in the action stage in the intervention group, the percentage of those with adequate intake of fruits and vegetables was significantly increased in the intervention group.

Achieving or maintaining any positive behavioural change especially among overweight and obese school children is an arduous challenge. The respondents generally moved to different stages after the NEI. The application of TTM to study fruit and vegetable intake behaviour in our study required respondents to answer whether they were currently consuming at least five servings of fruits and vegetables daily for the past six months. In our study, school children who were at the maintenance stage in the intervention group had reduced from $38.9 \%$ to $34.9 \%$, which indicated some relapse. Thus, relapse to previous behaviours may occur at any stage and various factors may contribute to this. Any intervention programme usually consists of several methods including some practical aspects, while others may focus only on theoretical approaches. Irrespective of the approach used, the 
respondents should have high motivation and emotional strength in order to avoid possible temptations that could lead to a relapse between state of changes (Prochaska \& Velicer, 1997; Purswani et al, 2017). A study by Gur et al (2019) among school children aged 9-15 years old in Istanbul however showed no relapse was observed during the followup period for the intake of fruits and vegetables. Since our study focused only on school-based intervention and not multi-component interventions at both home and school, it was rather challenging in designing the intervention that suited the level and stages of change of these school children. Apart from that, this relapse is possibly attributed by the lack of a school environment that supports the consumption of fruits and vegetables such as the availability or free access to fruits and vegetables in the school canteen, and also the lack of parental support to eat adequate fruits and vegetables at home. Despite these constraints, the application of TTM to facilitate the behavioural change for consumption of fruits and vegetables among overweight and obese school children in our study can be very beneficial. In our study, MyBFF@, School with NEI had some positive effects in increasing the intake of fruits and vegetables among overweight and obese school children, both at the preaction and action stages of change, after six months of participation in the programme.

The ability of nutrition education to help form positive attitudes towards healthy eating habits in children is recognised, although these attitudes are applied in practice less frequently (Stojan, Janez \& Verena, 2012). Our study revealed that NEI had a different impact on the intake of fruits and vegetables among obese and overweight secondary school children according to their stages of change. At certain TTM stages, NEI formed a positive attitude towards eating fruits and vegetables, but there were also an increase in negative attitudes after NEI. In our study, NEI was shown to benefit secondary school children at pre-contemplation stage, which eventually formed positive attitudes towards fruits and vegetables after the intervention. Previous study noted that nutrition education did not always exert a positive influence on a person's nutrition behaviour, however, such intervention could affect their attitudes, intentions and other factors that may influence their behaviour indirectly (Conner \& Armitage, 2002). A positive attitude towards healthy eating habits encourages school children to follow the daily recommendations as healthy habits, which subsequently leads to a healthy body and life (Harrington, 2016).

As for the strengths of the study, this study was designed as a randomised cluster controlled trial and has taken into consideration several parameters such as ethnicity and strata (urban versus rural). Therefore, it was representative of the Malaysian population and the findings of the study can be adopted or inferred to other schools in the country. However, our study's limitation was the challenge of ensuring full participation of school children in the intervention activities, especially among urban school children due to logistic problems, apart from the lack of involvement from parents.

\section{CONCLUSION}

MyBFF@school with NEI based on TTM had positive effects on the adequate intake of fruits and vegetables among obese and overweight secondary school children. The application of TTM helped us to understand the behaviours or attitudes of these children towards fruits and vegetables for the development 
of a better and more effective obesity intervention programme. It is suggested that parents, teachers, and school administration work together to ensure a supportive environment, with the implementation of multi-component interventions to provide continuous access or availability to fruits and vegetables at home and school for school children.

\section{Acknowledgements}

The authors would like to thank the Director General of Health Malaysia for his permission to publish this article and the Ministry of Education for giving the approval for us to undertake this study. We would also like to thank and acknowledge the tremendous support from all MyBFF@school research members including all the research officers and assistants. We also would like to express our appreciation to all the students, teachers and parents, as well as staffs of the Ministry of Health, District Health Office/health clinics and local universities that have directly or indirectly involved in this study. With their strong support and commitment, this research was possible. This research received funding from the Ministry of Health, Malaysia (NMRR-13-43916563).

\section{Authors' contributions}

$\mathrm{RS}$, principal investigator for nutrition component, conceptualised and designed the study, administered the data collection, conducted the data analysis, prepared the draft manuscript and reviewed the manuscript; NAAA, JR, NZ, WNAWM and ANI contributed to conception and design, interpretation and preparation of the draft manuscript; AY contributed to conceptualisation, formal analysis, methodology and writing of the review; MYJ, FMZ, ZI and AHM contributed to conception and design and providing critiques.

\section{Competing interests}

The authors declare that they have no competing interests.

\section{References}

Connor M \& Armitage CJ (2002). The Social Psychology of Food (pp. 175). Open University Press, Buckingham.

Davoodi SH, Hosseini Z, Aghamolaei T, Zare M \& Ghabarnejad A (2017). Fruit and vegetables consumption in High School Students in Bandar Abbas, Iran: An application of the Trans-theoretical Model. Arch Iran Med 20(6):334-349.
Greene GW, Fey-Yensan N, Padula C, Rossi S, Rossi JS \& Clark PG (2004). Differences in psychological variables by stage of change for fruit and vegetables in older adults. J Am Diet Assoc 104:1236-1243.

Gur K, Erol S, Kadioglu H, Ergun A \& Boluktas $R$ (2019). The impact on adolescents of a Transtheoretical Model-based programme on fruit and vegetable consumption. Public Health Nutr 22(13):2500-2508.

Harrington EM (2016). Fruit and Vegetable Intake, Attitudes, and Beliefs of Multicultural Middle School Students in Central Massachusetts. Master [Thesis]. University of Massachusetts Amherst, Massachusetts.

Harris PA, Taylor R, Thielke R, Payne J, Gonzalez N \& Conde JG (2009). Research electronic data capture (REDCap) - A metadata-driven methodology and workflow process for providing translational research informatics support. J Biomed Inform 42(2):377-381.

IPH (2017). National Health and Morbidity Survey (NHMS) 2017: Adolescent Nutrition Survey, Malaysia. Institute for Public Health, Ministry of Health Malaysia, Kuala Lumpur.

IPH (2013). National Health and Morbidity Survey (NHMS) 2017: Malaysian School-based Nutrition Survey 2012. Institute for Public Health, Ministry of Health Malaysia, Kuala Lumpur.

Johnson SS, Paiva AL, Cummins CO, Johnson JL, Dyment SJ, Wright JA, Prochaska JO, Prochaska JM \& Sherman K (2008). Transtheoretical model-based multiple behaviour intervention for weight management: effectiveness on a population basis. Prev Med 46(3):238-246.

Povey R, Conner M, Sparks P, James R \& Shepherd R (1999). A critical examination of the application of the Trans-theoretical Model's stages of change to dietary behaviours. Health Educ Res 14(5):641-651.

Prochaska JO \& Velicer WF (1997). The transtheoretical model of health behaviour change. Am J Health Promot 12(1):38-48.

Purswani P, Lazorick S, Fang $X$ \& Hardison GT (2017). Effect of school-based wellness intervention in 7 th graders on stage of change for lifestyle behaviours: The MATCH programme. J Child Obes 2:4:1-10.

Stojan K, Janez J \& Verena K (2012). The influence of nutrition education on the food consumption and nutrition attitude of school children in Slovenia. US-China Education Review A 11:953-954. 
Vakili V \& Khadem-Rezaiyan M (2016). Predictors of stages of change in fruit/vegetable consumption based on trans-theoretical model: a population-based study. Nutrition and Food Sciences Research 3(4):13-21.

van't Veer P \& Kampman E (2007). Food, Nutrition, Physical Activity, and the Prevention of Cancer: a global perspective. World Cancer Research Fund/American Institute for Cancer Research, Washington DC. From http://edepot.wur. nl/ 183651 [Retrieved September 4 2019].

Wafa SW, Talib RA, Hamzaid NH, Mccoll JH, Rajikan R, Ng LO, Ramli AH \& Reilly JJ (2011). Randomised controlled trial of a good practice approach to treatment of childhood obesity in Malaysia: Malaysian Childhood Obesity Treatment Trial (MASCOT). Int $J$ Pediatr Obes 6:e62-e69.
Wong CY, Mohd Shariff Z, Kandiah M, Taib M \& Nasir M (2014). Stages of change to increase fruit and vegetable intake and its relationships with fruit and vegetable intake and related psychosocial factors. Nutr Res Pract 8(3):297303.

WHO (2005). Non-communicable Disease and Mental Health Cluster, WHO STEPS Surveillance Manual: The WHO STEPwise approach to chronic disease risk factor surveillance/ Noncommunicable Diseases and Mental Health, World Health Organization. World Health Organization, Geneva. 